\title{
Target configuration and visibility
}

\author{
S. M. LURIA and BERNARD L. RYACK \\ Naval Submarine Medical Research Laboratory, Groton, Connecticut 06349
}

\begin{abstract}
Short, wide lights are more visible than long, narrow lights of the same total area to observers in the water without a face mask.
\end{abstract}

There has been a considerable amount of research on the relative identifiability of different shapes (Semple, Note 1). Most of the experiments have compared geometric forms, such as circles, squares, and triangles, and a number of studies have concluded that triangles are the most easily identifiable shapes. Such studies do not provide an answer to the following practical problem.

There are now plans to install lights around the emergency escape hatches of military helicopters to facilitate escape when the helicopter crashes at sea. When they crash in the water, these top-heavy aircraft quickly invert and sink, leading to considerable disorientation and difficulty in finding the escape hatches because of turbidity and darkness. Lights that function under water are, therefore, necessary.

One of the lights under consideration is the electroluminescent panel. These can be manufactured in any shape. The amount of power required depends on the total area to be illuminated rather than on the complexity of shape. The question arises, for a given area, is a long and narrow configuration more visible than a short and wide one, or is shape immaterial? Relatively few studies bear on this problem.

Helson and Fehrer (1932) presented different black forms of equal area against a light background and determined three sets of thresholds: the luminance threshold for the detection of the presence of light, the luminance at which the subjects realized that a geometric form was present, and the luminance thresholds for the identification of the forms. They found that the thresholds for the identification of the different forms varied considerably. The visibility threshold for the rectangle was better than that for the square; indeed, it was the best of the six shapes tested. There were almost no differences between the thresholds for the detection of the presence of light around the forms.

Hochberg, Gleitman, and Macbride (1948), on the other hand, measured visibility thresholds for lighted shapes of equal area on a dark background and concluded that more compact figures were most visible.

We thank Jo Ann S. Kinney for her valuable comments on an earlier draft. This study was funded by the Naval Air Development Center, Warminster, Pennsylvania, as part of the Helicopter Emergency Egress Lighting Program.
That is, a square would be more visible than a rectangle.

Lamar, Hecht, Shlaer, and Hendley (1947) measured visibility thresholds for lighted rectangles against a dark background and also concluded that for a given area, threshold improves as the target shape approaches a square.

Yet Wulfeck, Weisz, and Raben (Note 2) cite a study by Meetham and Lambert in which luminance thresholds were obtained for lighted circular and elliptical forms. The investigators concluded that shape did not affect visibility.

On the basis of these studies, it is impossible to be certain which shape would be better. Moreover, in view of the fact that the occupants of helicopters would presumably not be carrying scuba masks under water, they would not be able to differentiate geometric forms (Luria \& Kinney, 1970, 1975). We have, therefore, measured the visibility thresholds of subjects under water without a face mask for lights of various shapes and areas.

We have found that, in fact, the short, wide light is more visible than the long, narrow one of the same area under these conditions.

\section{METHOD}

Two electroluminescent panels, $2 \times 10$ in. were mounted end to end to make one light $2 \times 20$ in. This was partially masked in various ways with black tape to produce the configurations shown in Figure 1. The luminance threshold of subjects in the water without a face mask was measured in water whose coefficient of turbidity $(a)$ was about 2.5 . That is, the water was quite turbid, comparable to water in a harbor. Threshold intensity was measured both for the double panel and for one panel completely exposed, one or two panels three-quarters exposed, half exposed, and one-quarter exposed.

The subject was positioned $10 \mathrm{ft}$ from the darkened lights, and their intensity was slowly increased by means of a rheostat until he signaled that he could see the light. For each configuration, several such determinations were made for two subjects.

\section{RESULTS}

The results, shown in Figure 1, indicate that shorter, wider lights are more visible than longer, narrower lights. Three comparisons among the eight thresholds lead to this conclusion. First, the $2 \times 10$ in. panel (A) and the $1 \times 20$ in. panel (C) both comprise 20 in. $^{2}$ of lighted surface; the former gave the lower threshold. 


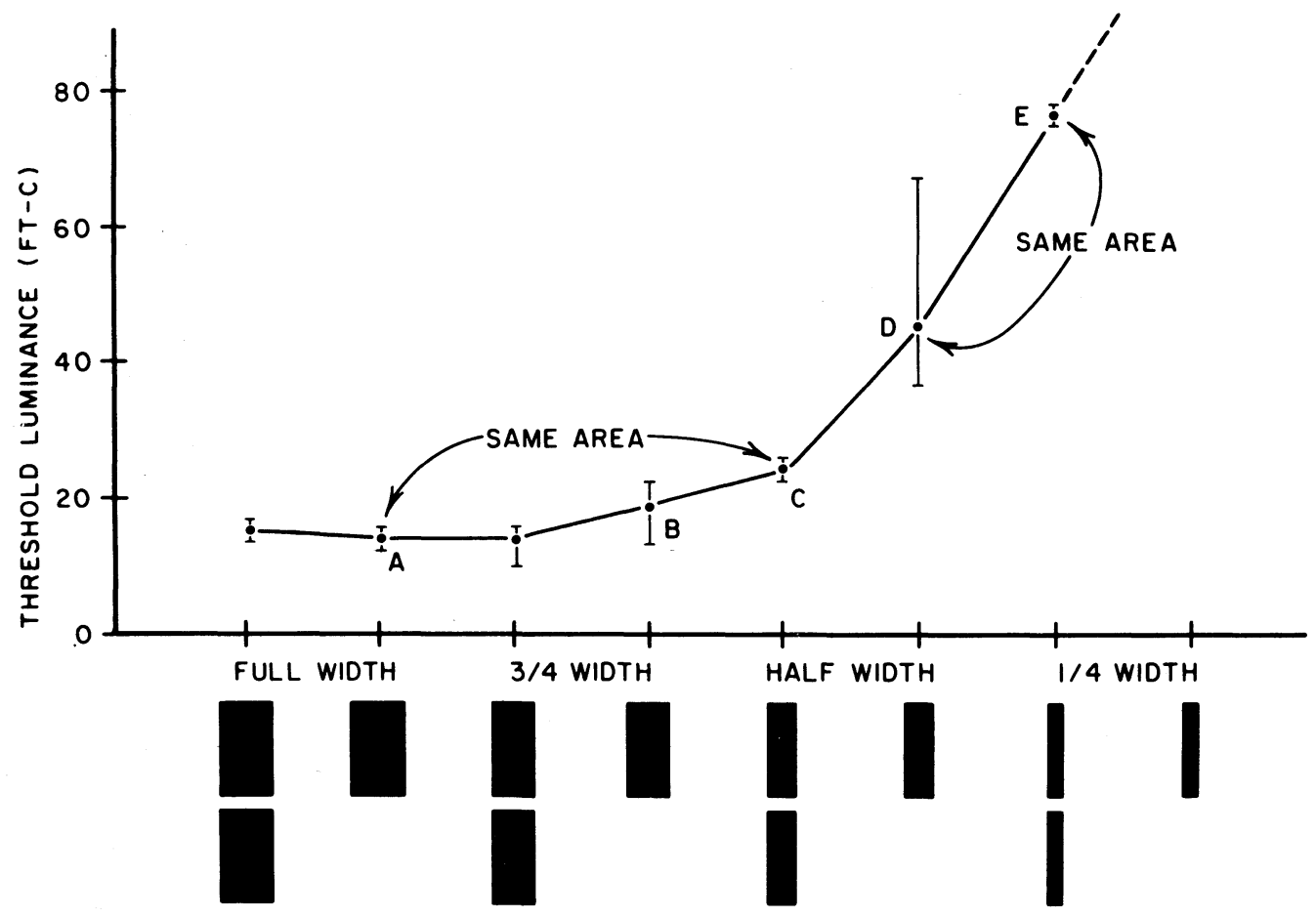

Figure 1. Mean luminance thresholds for electroluminescent panels of various lengths and widths. The vertical bars encompass the total range of responses.

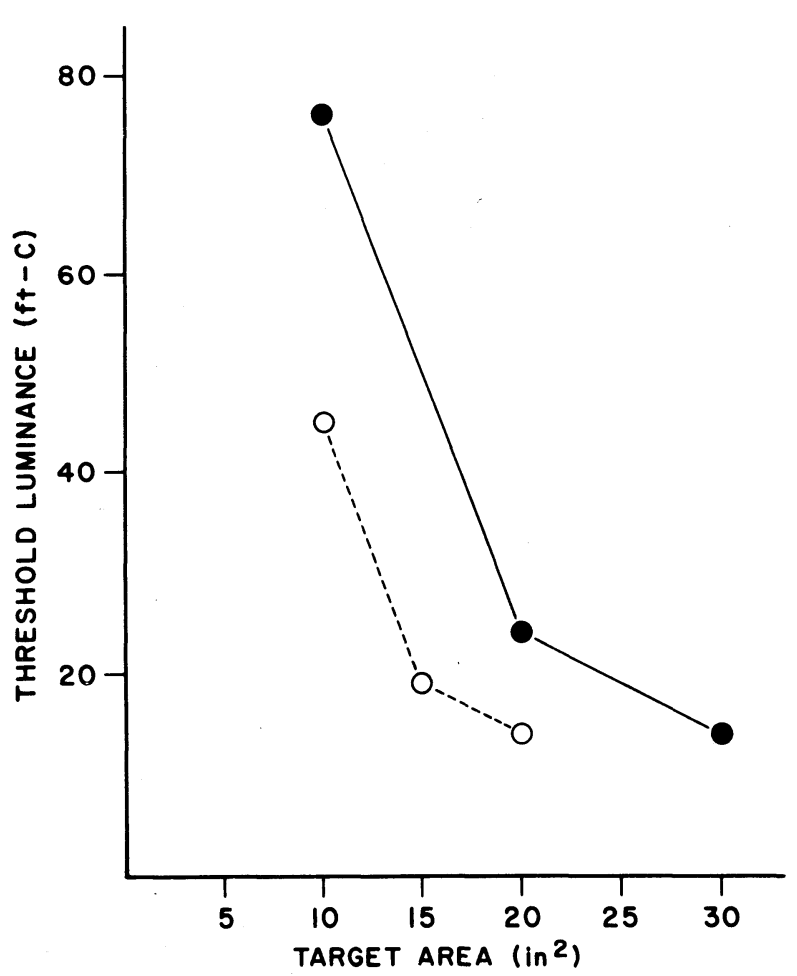

Figure 2. Luminance thresholds as a function of target area. Thresholds for long, narrow targets are represented by the filled circles; thresholds for short, wide targets are represented by open circles.
Second, the $1 \times 10$ in. panel (D) and the $.5 \times 20$ in. panel (E) both have 10 in. $^{2}$ of surface, and again the shorter, wider panel gave the lower threshold. Third, consider the $1.5 \times 10$ in. panel (B) and the $1 \times 20$ in. panel (C). In this case, the latter presents a greater area of lighted surface, yet the mean threshold for the former is lower. Again, the shorter, wider panel was more visible. It should be noted that the vertical bars at each data point in Figure 1 are not standard deviations; they encompass the total range of settings. It is quite clear these means are different.

The luminance threshold obtained for each of the targets of interest as a function of their area are shown in Figure 2. The graph compares the thresholds for the long, narrow targets (solid circle) with those for short, wide targets (open circles) and clearly reveals the greater sensitivity to the latter.

\section{DISCUSSION}

These results can be related to the body of evidence that the mammalian visual system behaves as though it were a set of spatial filters that function as if being subjected to a Fourier analysis (Robson, 1975). According to Fourier analysis, as a stimulus is compressed, there is an increase in the higher frequencies in its frequency spectrum (Cornsweet, 1970; Lathi, 1965). Thus, compared to a wide stimulus, a narrow one would have a greater proportion of higher frequencies. Since an observer in the water without a face mask is a 60-diopter hyperope, the stimuli are extremely blurred (Luria \& Kinney, 1970, 1975). 
Under these conditions, the high frequencies in the stimuli will be lost (Campbell \& Green, 1965). As a greater proportion of high frequencies is added to the stimulus, a greater proportion of the stimulus energy will be lost, and visibility should decrease.

It is likely that the present effect depends on the size of the stimuli. Lamar et al. (1947) found this to be true for foveal stimuli; they found that sqaure targets were most visible with a stimulus area of $100 \mathrm{~min}^{2}$. In the human fovea, the receptive field centers are quite small, estimated to be about $18 \mathrm{~min}$ of arc (Jung, 1973). However, in the periphery (where the lights in the present experiment were undoubtedly falling), the receptive field size ranges up to about 3 or $4 \mathrm{deg}$ (Jung, 1973). And in the present experiment, the $2 \times 10$ in. panel nominally subtended $1 \times 5 \mathrm{deg}$ of visual angle, which was increased, of course, by the scatter of light in the turbid water and the inability of the eyes to focus in the water. Thus, the stimulus size was of the same order of magnitude as the receptive field size in the periphery. If the present effect depends on stimulating retinal areas equivalent to the size of the receptive fields, it may disappear as the lights become either too small or too large.

\section{REFERENCE NOTES}

1. Semple, C. A., Jr., Heapy, R. J., Conway, E. J., Jr., \& Burnette, K. T. Analysis of human factors data for electronic flight display systems (AFFDL Tech. Rep 70-174). WrightPatterson Air Force Base, Ohio, April 1971.

2. Wulfeck, J. W., Weisz, A., \& Raben, M. W. Vision in military aviation (WADC Tech. Rep. 58-399). Wright-Patterson Air Force Base, Ohio, November 1958, p. 239. (AD 207780)

\section{REFERENCES}

Campeell, F. W., \& Green, D. G. Optical and retinal factors affecting visual resolution. Journal of Physiology (London), 1965, 181, 576-593.

Cornsweet, T. N. Perception. New York: Academic Press, 1970. Helson, H., \& Fehrer, E. The role of form in perception. American Journal of Psychology, 1932, 44, 79-102.

Hochberg, J. E., Gleitman, H., \& Macbride, P. D. Visual threshold as a function of simplicity of form. American Psychologist, 1948, 3, 341-342.

JunG, R. Visual perception and neurophysiology. In R. Jung (Ed.), Handbook of sensory physiology Vol. 7/3): Central processing of visual information, Part A. New York: SpringerVerlag, 1973.

Lamar, E. S., Hecht, S., Shlaer, S., \& Hendley, C. D. Size, shape, and contrast in detection of targets by daylight vision. I. Data and analytical description. Journal of the Optical Society of America, 1947, 37, 531-545.

LATHI, B. P. Signals, systems and communication. New York: Wiley, 1965.

LuRiA, S. M., \& Kinney, J. A. S. Acuity-luminance function for extreme refractive error. American Journal of Optometry, 1970, 47, 205-211.

LuriA, S. M., \& Kinney, J. A. S. Vision in the water without a facemask. Aviation Space and Environmental Medicine, 1975, 48, 1128-1131.

Robson, J. G. Receptive fields: Neural representation of the spatial and intensive attributes of the visual image. In E. C. Carterette \& M. P. Friedman (Eds.), Handbook of perception (Vol 5): Seeing. New York: Academic Press, 1975. 